\title{
intuitio
}

Revista do PPG em Filosofia da PUCRS

http://dx.doi.org/10.15448/1983-4012.2019.1.32251

\section{O PROBLEMA DA TEORIA DAS ESPÉCIES E A ORIGEM DO CONHECIMENTO HUMANO EM TOMÁS DE AQUINO}

\author{
THE THEORY OF SPECIES PROBLEM AND THE ORIGIN OF \\ HUMAN KNOWLEDGE IN AQUINAS
}

Lucas Nogueira Borges'

Resumo: As discussões sobre a teoria das espécies em Aquino estão situadas em três interpretações que discorrem acerca das relações dos atos do intelecto humano com o objeto externo. A primeira interpretação refere-se à espécie como um modo de acesso direto ao objeto, em que o intelecto seria capaz de acessá-lo por sua própria natureza. A teoria das espécies de Tomás, nessa interpretação, é classificada como um realismo direto ingênuo. A segunda interpretação estabelece, ao contrário, um representacionalismo. As espécies não seriam o primeiro objeto da apreensão. No processo do conhecimento, o objeto exterior seria conhecido secundariamente. Uma terceira interpretação sobre as espécies é a de um realismo direto modificado. Essa interpretação sustenta que as espécies são recursos cognitivos necessários, não implicando diferenças com o objeto externo. $O$ intelecto visa o objeto externo. Por isso, o objeto externo é apreendido primariamente, enquanto a espécie, secundariamente, por um ato reflexivo. A proposta deste trabalho consiste em rever o debate entre Tomás e o platonismo acerca da origem do conhecimento humano, partindo dessas três interpretações descritas acerca das espécies inteligíveis. Num segundo momento, mostrar como as espécies inteligíveis podem ser tanto o id quod quanto o id quo, pois, no primeiro caso, a forma do objeto externo enquanto presente no intelecto

\footnotetext{
1 Universidade Federal de Uberlândia - UFU. ORCID: http://orcid.org/0000-0002-7160-3605
} 
é idêntica à forma do objeto externo no modo natural. No segundo caso, como a intelecção de algo material no modo imaterial necessita de um intermediário, mas não de um intermediário que seja o primeiro objeto de conhecimento intelectivo.

Palavras-chave: Teoria das espécies. Realismo. Representacionalismo. via Platonica. Tomás de Aquino.

Abstract: There are three interpretations on the theory of intelligible species. These interpretations debate the relationship between the species and the external object and explain the intellective act of the human soul. The first interpretation refers to the species as a way of direct access to the object, in which the intellect would be able to access it due to its own nature. Aquinas' species theory, according to this interpretation, is classified as a naive direct realism. The second interpretation states, to the contrary, a representationalism. The species would not be the first object of apprehension. In the process of knowing, the external object would be known secondarily. A third interpretation about species renders us a modified direct realism. This interpretation supports that species are necessary cognitive resources, and do not imply differences with the external object. The intellect aims for the external object. For this reason, the external object is primarily apprehended, while the species is apprehended by a reflexive act, therefore, secondarily. This paper aims to review the debate between Aquinas and Platonism about the origin of human knowledge on the assumption of these three interpretations on intelligible species. It aims subsequently to present how intelligible species can be both id quod and id quo, since in the first case the form of the external object - present in the intellect - is identical to the form of the external object in its natural form. In the second case, it demonstrates how the intellection of something material - in the immaterial form - needs an intermediary, however, not an intermediary which is itself the first object of intellective knowledge.

Keywords: Theory of Species. Realism. Representationalism. via Platonica. Aquinas. 


\section{1 - A QUERELA DO REALISMO DIRETO E DO REPRESENTACIONALISMO NA TEORIA DAS ESPÉCIES DE TOMÁS DE AQUINO}

Na teoria das species de Tomás de Aquino, investiga-se que tipo de acesso a percepção e o pensamento teriam dos objetos extra-mentais. Tal investigação pressupõe um realismo, cuja sustentação consiste na existência das coisas externas independentemente da percepção sensorial ou do pensamento. Pode-se dizer que a condição apresentada por Moore $^{2}$ esse é percipi não se enquadra como um problema para a teoria do conhecimento de Tomás. A coisa externa existe independente de qualquer dado sensorial, sensação, ideia, conceito, de qualquer entidade que seja condicionante para admitir a existência do objeto.

A primeira corrente que explica a relação entre e o intelecto e o objeto externo é o realismo direto. O ponto de sustentação do realismo direto é que, em condições normais, os atos da percepção e do pensamento se dirigem diretamente aos objetos no mundo, quer dizer, não se voltam para dados sensíveis, ideias, objetos intencionais, ou qualquer coisa que esteja inserida entre o cognoscente e o cognoscível. Um dos representantes dessa teoria é Norman Kretzmann, que sustenta ser o acesso à coisa externa completamente direto e que a cognição das coisas hilemórficas é natural para o intelecto humano, caracterizando Tomás como um realista direto ingênuo ${ }^{3}$.

Uma defesa mais elaborada do realismo direto na teoria tomista do conhecimento é feita por Baltuta ${ }^{4}$, em que ela expõe o papel das espécies

\footnotetext{
2 AMATUCCI, Marcos. A refutação do idealismo. Synesis, Petrópolis, v. 7, n. 2, 2015, p. 116-188, jul./dez. 2015. Tradução de MOORE, G. E. The refutation of idealism. Disponível em: http:// seer.ucp.br/seer/index.php/synesis/article/view/908/432. Acesso em: 20 set. 2018.

3 KRETZMANN, Norman. Philosophy of mind. In: KRETZMANN, Norman; STUMP, Eleonore (org.). The Cambdridge companion to Aquinas. 5th ed. Cambridge: Cambridge University Press, 1998. p. 128-160.

4 BALTUTA, Elena. Aquinas on intellectual cognition: the case of intelligible species. Philosophia, [s. I.], v. 41, n. 3, p. 589-602, Sept. 2013. Disponível em: http://dx.doi.org/10.1007/s11406-0139481-y. Acesso em: 20 set. 2018.
} 
no processo cognitivo humano. Para Baltuta5, há muito mais argumentos a favor do realismo direto do que para o representacionalismo. Isso ocorre porque a base do realismo direto é a tese da identidade formal. O realismo direto em Tomás de Aquino é sustentado pela tese da identidade formal, que se baseia na capacidade do intelecto de se tornar idêntico ao objeto. Segundo essa teoria, as espécies são intermediários causais que não implicariam diferença entre o objeto no mundo externo e sua apreensão cognitiva.

A segunda interpretação sustenta que Tomás é um representacionalista. Neste caso, o acesso ao objeto extra-mental se dá indiretamente (realismo indireto). Como os objetos externos seriam apreendidos apenas pela mediação da espécie, as coisas externas não podem ser o primeiro objeto da cognição. Pasnau ${ }^{6}$ sustenta uma teoria realista em que as espécies, além de representarem o mundo externo, são ainda os objetos primários dos atos cognitivos do intelecto. Outro defensor do representacionalismo em Tomás é Claude Panaccio. Para ele ${ }^{7}$, a teoria da cognição intelectual de Tomás não é compatível com o realismo direto. O ponto estrutural de sua argumentação parte da afirmação de que qualquer teoria cognitiva que atribua um papel importante e indispensável para representações mentais deve ser considerada uma teoria representacionalista. Uma representação mental é um tipo de marca que está numa mente individual repleta de um conteúdo semântico referente a coisas externas. Em sua argumentação, a espécie inteligível e o verbo mental não podem ser a quididade da coisa. A cognição da coisa conhecida ocorre em virtude de uma relação de similitude entre a espécie inteligível e a coisa externa, em que a espécie é um intermediário inteligível no intelecto. $\mathrm{O}$ intelecto conhece apenas a

5 BALTUTA, Elena. Aquinas on intellectual cognition: the case of intelligible species. Philosophia, [s. I.], v. 41, n. 3, p. 589-602, Sept. 2013. Disponível em: http://dx.doi.org/10.1007/s11406-0139481-y. Acesso em: 20 set. 2018.

6 PASNAU, Robert. Theories of cognition in the later middle ages. Cambridge: Cambridge University Press, 1997, p. 195-219.

7 PANACCIO, Claude. Aquinas on Intellectual Representation. Cahiers d'Épistémologie, Montréal, n. 265, p. 03-21, 2000. Disponível em: https://www.yumpu.com/en/document/read/27600278/ cahiers-dapistamologie-uqam. Acesso em: 03 jan. 2019. 
similitude da coisa que é entendida, nesse caso, como uma marca mental particular e acidental. Por essa razão, a espécie inteligível é acidental e particular. O intelecto recorre primariamente à intenção inteligida, ou seja, apreender a forma de um ente significa apreender a similitude de tal ente. $O$ que o intelecto apreende da coisa é a similitude que não é propriamente a quididade dela, mas um acidente mental. Nesse sentido, a espécie inteligível refere-se à coisa externa, a qual representa. No entanto, não pode haver uma identidade formal, pois a espécie inteligível é diferente da forma que existe materialmente na coisa.

A terceira interpretação apresenta-se como uma proposta intermediária entre o realismo direto e indireto. Defendido por Perler, o realismo direto modificado sustenta que as espécies são recursos cognitivos necessários para a apreensão dos objetos no mundo ${ }^{8}$. Primariamente, apreendem-se os objetos externos com o auxílio de entidades cognitivas. Secundariamente, as entidades cognitivas, a saber, as espécies sensível e inteligível, são apreendidas por meio de um ato de reflexão. Para o representacionalismo, sustenta Perler, no processo cognitivo, apreende-se, primariamente, uma entidade cognitiva. O objeto externo só pode ser apreendido como causa dessa entidade cognitiva, quer dizer, é concluído por raciocínios de causa. Essa posição representacionalista não nega que a espécie seja um mediador, estando entre a coisa externa e o intelecto.

Perler afirma que os intérpretes acabam por endossar um representacionalismo na teoria das espécies porque Tomás, no Comentário às Sentenças de Pedro Lombardo, teria insinuado que o primeiro conhecido seria a similitude da coisa e, posteriormente, a coisa no mundo externo:

Deve-se saber, contudo, que o conhecido é dito duplamente, assim como o visto. Há, de fato, a primeira coisa vista que é a própria espécie da coisa visível existente na pupila. Essa é,

8 PERLER, Dominik. Theorien der Intentionalität im Mittelalter. 2nd ed. Frankfurt Am Main: Vittorio Klostermann, 2004, p. 80-89. 
também, a perfeição da coisa vista, o princípio da visão e a luz, o meio da coisa visível. E há a segunda coisa vista que é a própria coisa fora da alma. Similarmente, o primeiro conhecido é a própria similitude da coisa, que está no intelecto, e o segundo conhecido, a própria coisa, que é conhecida por sua similitude. ${ }^{9}$

De acordo com essa passagem, o primeiro objeto apreendido pelo intelecto é a species, e o segundo objeto é a coisa externa, que é apreendida somente através da espécie. É preciso formar a espécie da coisa, que é a similitude, para então apreender a coisa externa.

A solução de Perler para essa passagem consiste na diferenciação entre os modos de existência. Perler sustenta que não devem se supor, nessa passagem, duas entidades distintas, mas dois modos de existência de uma mesma coisa. A coisa pode existir num modo natural e material fora do intelecto e de um modo imaterial no intelecto. A natureza de uma coisa pode existir materialmente segundo o que está na matéria natural e imaterialmente segundo o intelecto. Essa diferenciação do modo de existência não implica uma diferença entre a coisa material e a coisa existindo no intelecto. Enquanto conteúdo, não se trata de duas entidades distintas. Trata-se, pelo contrário, de dois modos de existência de um único objeto. Fora do intelecto, a forma que configura a coisa existe num modo material. Dentro do intelecto, ela existe no modo imaterial. O primeiro conhecido é o conteúdo de uma espécie, ou seja, a natureza ou a forma da coisa, enquanto ela existe imaterialmente no intelecto. $O$ segundo conhecido é a própria forma ou natureza, enquanto existe no mundo material. Isso não

\footnotetext{
9 Tradução do autor. No original: "Sciendum tamen est, quod intellectum dupliciter dicitur, sicut visum etiam. Est enim primum visum quod est ipsa species rei visibilis in pupila existens quae est etiam perfectio videntis, et principium visionis, et medium lumen rei visibilis. Et est visum secundum, quod est ipsa res extra animam. Similiter intellectum primum est ipsa rei similitudo, quae est in intellectu et est intellectum secundum ipsa res, quae per similitudinem illam intelligitur." In: THOMAS \& ALARCÓN, E. S. Thomae de Aquino Opera omnnia: Scriptum Super Sententiis, Liber 1, Distinciones 35, Quaestio 1, Articulus 2. Pamplona: Pampilonae, Ad Universitatis Studiorum Navarrensis. 2001. Disponível em: http://www.corpusthomisticum. org/iopera.html. Acessado em: 20 de setembro de 2018.
} 
significa que haveria dois momentos, um momento em que se apreenderia uma entidade interior e um momento em que se concluiria a coisa externa. O cerne dessa argumentação consiste na afirmação de que a espécie não é uma duplicação no intelecto do objeto material, quer dizer, um sósia, uma cópia da coisa. Além disso, isso resultaria numa duplicidade do objeto: as espécies como objetos internos e a coisa externa como objeto externo. Por essa razão, pode-se dizer que há apenas um voltar-se (conversio) para a coisa e para a espécie. Não há um acesso de uma entidade interna e representativa para uma entidade externa representada. Pelo contrário, há uma única apreensão da espécie e do objeto externo. Isso significa, que no tocante ao conteúdo, a espécie não é outra coisa que a natureza instanciada no objeto material. Na medida em que se apreende a espécie, ele apreende a natureza do objeto pela espécie ${ }^{10}$.

Perler ilustra a noção de modos de existência e a noção de conversio com o exemplo de uma foto. Ao olharmos para uma foto com pessoas em férias, referimo-nos diretamente às pessoas da foto. A referência direta às pessoas só é possível porque as vemos diretamente enquanto elas são apresentadas na foto. Isso significa que o conteúdo da foto é idêntico ao conteúdo dessas pessoas, ainda que haja dois modos de existência, pois na foto as pessoas existem apenas no papel e, no mundo real, existem em carne e osso. A analogia da foto mostra que uma mesma coisa pode estar em dois modos distintos ${ }^{11}$. Ainda que haja elementos da sensibilidade

10 PERLER, Dominik. Theorien der Intentionalität im Mittelalter. 2nd ed. Frankfurt Am Main: Vittorio Klostermann, 2004.

$"$ Dois pontos devem ser considerados acerca da analogia da foto proposta por Perler: o primeiro ponto é o modo de existência de uma coisa. O segundo ponto é se o modo de existência de uma coisa pode implicar uma impossibilidade de referência. A espécie é um recurso cognitivo, quer dizer, precisamos dela para conhecer as coisas. Entretanto, ela como entidade cognitiva é, ao mesmo tempo, a forma da coisa instanciada no modo intencional ou espiritual. Por conseguinte, quando olhamos a foto, vemos o que está na foto e reconhecemos o que está na foto e nos referimos às coisas que estão na foto, podendo até fazer certas afirmações sobre elas. De acordo com essa analogia, há apenas um voltar-se para o conteúdo da espécie e para o objeto externo. A pergunta decisiva é se compreendemos esse conteúdo, enquanto ele existe no intelecto ou enquanto ele existe no mundo. Segundo a interpretação de Perler, a compreensão desse conteúdo se dá enquanto ele existe no intelecto e enquanto ele se refere à coisa existente no mundo. $\mathrm{O}$ intelecto, por sua vez, só apreende a forma de uma coisa ao modo 
conectados na foto, como cores e proporções, o exemplo da foto esclarece a possibilidade de referência a uma mesma coisa em modos diferentes. $O$ intuito dessa analogia é mostrar que a espécie, seja sensível ou inteligível, desempenha o papel de um device, um recurso cognitivo.

Segundo Perler ${ }^{12}$, a intencionalidade na teoria de Tomás se dá em três níveis: no nível sensorial, no nível intelecto e no nível semântico. Em todos esse níveis, trata-se apenas de um único objeto. A espécie sensível é, portanto, a apreensão das propriedades particulares da coisa, enquanto a espécie inteligível, que decorre do ato de abstração do intelecto, é a quididade da coisa. Contudo, conforme o autor, não há dois objetos, mas apenas um objeto em níveis distintos de referência. O intelecto ou a imaginação, em Tomás, se dirigem ao objeto externo, por meio das espécies.

O ponto de sustentação do realismo direto modificado defendido por Perler consiste na tese da identidade formal'3 ${ }^{13}$ a qual sustenta a espécie instanciada no intelecto é idêntica à forma instanciada na coisa. A espécie, por sua vez, encontra-se no modo imaterial e espiritual, enquanto a forma instanciada na coisa externa está misturada com a matéria e, por isso, está no ser natural (esse naturalis).

Parte-se desse debate acerca dos tipos de realismo, com os quais a teoria das espécies de Tomás de Aquino tem sido interpretada, para mostrar que as teses platônicas do conhecimento, contra as quais Tomás argumenta nas Q. 84 e 85 da Suma de Teologia, propõem uma diferença entre o objeto externo (corpus) e a ideia (idea), mas não entre a espécie enquanto conteúdo, pois a espécie só se realiza no intelecto a partir do contato com o objeto externo. Uma vez que não endossa as ideias como

que lhe compete, quer dizer, abstraindo de modo imaterial a forma da coisa externa no mundo e das condições materiais individuantes, que são as características sensíveis.

12 PERLER, Dominik. Theorien der Intentionalität im Mittelalter. 2nd ed. Frankfurt Am Main: Vittorio Klostermann, 2004.

13 PERLER, Dominik. Essentialism and direct realism: some late medieval perspectives. Topoi, Amsterdan, v. 19, n. 2, p. 111-122, Dec. 200o. Disponível em: http://dx.doi.org/10.1023/a:1006425008627. Acesso em: 13 set. 2018. 
origem do conhecimento humano, Tomás de Aquino as estabelece como conhecimento da ordem divina, de modo que o conhecimento humano se dê nos objetos externos.

Outra justificativa para essa análise a partir das teses platônicas é a expressão "véu das espécies". Com essa expressão, pretende-se dizer que o acesso às coisas do mundo nunca é direto, mas se dá através de intermediários. Ver algo através de um véu significa que não podemos ver a coisa tal como ela é; nós a vemos sempre com graus de distorção. Nesse sentido, Pedro João Olivi, teólogo franciscano do século XIII, criticou severamente a teoria das espécies de Tomás, questionando como o intelecto poderia se referir ao objeto diretamente, se tivesse que primeiro "olhar" para a espécie ${ }^{14}$.

\section{2 - A QUESTÃO 84 DA SUMA TEOLÓGICA E AS VIAS PLATÔNICAS}

Frequentemente, os debates em torno da interpretação da teoria das espécies de Tomás de Aquino não consideram a contenda com as vias platônicas como ponto de partida para a solução do problema do tipo de realismo que a teoria das espécies de Tomás apresenta. Pretende-se mostrar que o conhecimento dos corpos é impreterível ao conhecimento humano. Tomás esclarece porque a interpretação dos primeiros filósofos acerca dos corpos externos se equivoca e como Platão não foi capaz de explicar os processos do conhecimento humano sem estabelecer uma realidade distinta da realidade material. Obviamente, Tomás de Aquino argumenta contra a teoria dos árabes acerca do intelecto e revela enorme influência da teoria metafísica e noética de Aristóteles. A contenda com Platão e o platonismo permite diferenciar os fundamentos da teoria do

\footnotetext{
14 Para uma leitura detalhada sobre o problema do véu das espécies em Tomás de Aquino e a recepção do representacionalismo na filosofia medieval e moderna, ADRIAENSSEN, Han Thomas. Representation and scepticism from Aquinas to Descartes. Cambridge: Cambridge University Press, 2017.
} 
conhecimento de Tomás e por que o objeto do intelecto são os corpos e não exatamente uma ideia imaterial ou entidades mentais.

Como a Questão 84 da primeira parte da Suma Teológica investiga a origem do conhecimento humano, cujo resultado consiste na tese de que o conhecimento se origina da experiência sensível, as coisas no mundo externo como ponto de partida do conhecimento humano exige que as espécies sejam distintas de ideias e que o intelecto tenha acesso à coisa no mundo externo. Tomás assente que a alma unida ao corpo pode conhecer as coisas corpóreas. Tal pressuposição visa refutar as teses do platonismo acerca do conhecimento, principalmente, a tese de que o conhecimento se origina das ideias das coisas. Pelo viés platônico, o intelecto humano não pode conhecer os corpos, mas somente as ideias diretamente e nelas próprias (Q. 84, art. 1, ad 1; art. 5 ad.3). Entretanto, qual o fundamento dessa tese e quais as implicações de sua negação.?

Henle denominou por vias platonicas formulações comumente atribuídas a Platão e aos platônicos. Em seu capítulo A teoria do conhecimento humano de Platão, apresenta o esquema das Questões 84 e 85 da primeira parte da Suma, contrastando a doutrina platônica com a dos filósofos antigos. As teses platônicas que fundamentam os pontos da via platônica na Questão 84 e 85 são as seguintes: a mutabilidade das coisas materiais; o engano dos sentidos; a impossibilidade do conhecimento dos corpos pelo intelecto; as ideias são conhecidas diretamente e nelas próprias; o intelecto conhece a quididade das substâncias separadas (Q. 88, 1 art.1); o corpo não pode atuar sobre a alma15 .

Nesse sentido, a relação entre Tomás e o platonismo se assenta numa base comum do conhecimento, a saber, a discussão da possibilidade do conhecimento e da natureza do objeto do conhecimento humano. Não importa apenas saber se o realismo tomista sugere cognição direta ou indireta de uma coisa externa, mas também, a partir disso, quais as relações do cognoscente

15 HENLE, R. J. Saint Thomas and platonism: a study of the plato and platonici texts in the writings of Saint Thomas. The Hague: Martinus Nijhoff, 1970, p. 394. 
com o seu objeto e quais as implicações resultantes do abandono do modelo platônico para a escolástica medieval posterior. Nas palavras de Henle:

Em resumo, na questão 84 (e, de fato, ao fim da questão 84) há uma investigação sistemática do conhecimento humano, na qual deliberações definitivas são apresentadas em contraste claro e consciente com as posições de Platão e dos Platonistas. Portanto, o que podemos afirmar sobre o entendimento de São Tomás ao abordar esta questão? Não devemos dizer apenas que ele havia feito sua própria escolha, mas também que havia decidido que sua principal oposição teórica estava presente no Platonismo, e que a escolha fundamental não envolvia Agostinho, ou Avicena, ou Avempace, ou qualquer outro, mas sim Platão, que apoiava a todos eles em oposição ao seu próprio Aristóteles? Assim, enfatiza-se a singular importância destes artigos (84 a 88) que sozinhos, nos trabalhos originais de São Tomás, constituem uma investigação sistemática ex professo estendida do conhecimento humano ${ }^{16}$.

A oposição teórica de Tomás tinha como alvo a posição de Platão e dos platônicos na questão da origem de todo nosso conhecimento e sua validade. Essa oposição pretendia mudar o estatuto ontológico das coisas naturais e a relação epistemológica do cognoscente com o cognoscível. A fonte do conhecimento passa a ser as coisas externas no mundo (extra

\footnotetext{
16 Tradução do autor. No original: "To summarize then: in the eighty-fourth question (and, indeed, to the end of the eighty-fourth question) there is a unique systematic investigation of human knowledge in wich definitive determinations are presented in clear-cut and conscious contrast to the positions of Plato and the Platonists. What can we say, therefore, of the mind of Saint Thomas as he approached this question? Must we not say not only that he that made a definitive choice himself but also that he had decided that his main theoretical opposition was in Platonism and that the fundamental option did not involve Augustine or Avicenna or Avempace or anyone else but rather the Plato who stood behind them all in opposition to his own Aristotle? Thus is emphasized the unique importance of these articles (eight-four to eight-eight) which alone in the original works of Saint Thomas constitute an extended ex professo systematic investigation of human knowledge." (HENLE, R. J. Saint Thomas and platonism: a study of the plato and platonici texts in the writings of Saint Thomas. The Hague: Martinus Nijhoff, 1970, p. 390-391).
} 
animam), em razão de sua configuração hilemórfica. Os princípios da via platonica precisam os objetos do conhecimento científico. Eles não podem ser encontrados no mundo sensível, de modo que todo conhecimento intelectual só pode se referir às ideias e às entidades matemáticas. As ideias, nesse sentido, são o objeto próprio da inteligência humana, sendo conhecidas primeiro e por si. Por essa razão, as ideias são inteiramente inteligíveis em ato. Platão não precisa de um intelecto agente que torne inteligíveis os dados dos sensíveis. Pelo contrário, deve-se destacar que as ideias, como são imateriais e conhecidas primeiro e por si, são apresentadas à mente como já efetivamente inteligíveis. Além disso, na teoria platônica apresentada em Tomás, as ideias podem ser entendidas como causa imediata das espécies, de forma que o conhecimento está constantemente presente na alma humana imaterialmente. De acordo com essa linha de raciocínio, o intelecto está repleto de espécies inteligíveis, entretanto, devido à sua união com o corpo, encontra-se impedido de seu ato intelectivo. Segundo Tomás: “(...) Platão sustentou que o intelecto humano está naturalmente pleno de todas as espécies inteligíveis, mas é impedido, pela união do corpo, não podendo elevar-se ao ato ${ }^{17}$."

Os sensíveis, por outro lado, são inteiramente eliminados como fonte do conhecimento humano e não se configuram como um objeto para o intelecto humano. Por dois aspectos, os corpos sensíveis são rejeitados como fonte segura e causa do conhecimento intelectivo. Primeiramente, devido à inconstância das coisas sensíveis que se encontram no mundo material, possuem um modo distinto do modo do intelecto. Em segundo lugar, devido à natureza dos sentidos, que diverge da natureza do intelecto. Os sentidos são falhos, enquanto o intelecto é da ordem do conhecimento noético, quer dizer, encontra-se no nível das ideias. Como o intelecto possui conhecimento, naturalmente, graças à participação na ideia, a interpretação platônica é de que o modo de conhecer é idêntico ao

17 AQUINO, Tomás de. Suma de Teologia: primeira parte - questões 84-89. Tradução: Carlos Arthur Ribeiro Nascimento. 2. ed. Uberlândia: Edufu, 2010, p. 93. 
modo de ser da coisa. A ideia possui ser necessário, universal e imutável. Por essa razão, o intelecto teria como seu objeto a ideia. Platão, segundo Tomás, identificou o modo de conhecer do intelecto com o modo da ideia: necessário, universal e imutável. Consequentemente, excluiu os objetos sensíveis e os sentidos como fonte do conhecimento epistêmico, uma vez que os corpos sensíveis estão num modo diverso do modo do intelecto.

Tomás recusa essa posição de que as ideias seriam a origem do conhecimento humano e estabelece que as coisas corpóreas podem ser conhecidas pelo intelecto humano. Disso, decorre que o objeto do intelecto humano devem ser os corpos no mundo.

Na Questão 84, art. 1, Tomás de Aquino está preocupado em demonstrar que o conhecimento intelectual pode alcançar as coisas externas. Ele, diversas vezes, apoia-se no argumento de que alguém que carece dos sentidos não realiza todos os processos do conhecimento. Além disso, apoia-se também no fato de que, sem o conhecimento dos corpos, não pode haver ciência das coisas naturais, o que é inaceitável para aqueles que seguem o programa aristotélico. Não é por uma ideia como a de natureza platônica que o intelecto se dirige a um objeto externo, mas por uma espécie inteligível. Para Baltuta ${ }^{18}$, a espécie inteligível, na teoria de Tomás, desempenha um papel causal no processo do conhecimento. Primeiro, é preciso do objeto externo para depois ter-se a espécie e não uma espécie para conhecer o objeto.

O conhecimento intelectivo possui um estatuto distinto das coisas corpóreas. Um dos argumentos que sustenta a tese de que a alma não pode conhecer os corpos pelo intelecto sustenta uma certa ordenação da potência ao objeto: "os sentidos estão para os inteligíveis assim como o intelecto para os sensíveis. A alma não pode de modo algum conhecer,

18 BALTUTA, Elena. Aquinas on intellectual cognition: the case of intelligible species. Philosophia, [s. I.], v. 41, n. 3, p. 589-602, Sept. 2013. Disponível em: http://dx.doi.org/10.1007/s11406-0139481-y. Acesso em: 20 set. 2018. 
pelos sentidos, o espiritual que é inteligível. Portanto, não pode conhecer de modo nenhum, pelo intelecto, os corpos que são sensíveis"19.

Tomás não descarta a ciência da natureza que trata do corpo mutável e esse ponto está em debate com o platonismo. Primeiro, o objeto externo não é considerado uma cópia e nem é algo por participação, mas contém em si tudo o que o seu ser permite em relação à sua existência, enquanto um composto de forma e matéria. Segundo, a espécie inteligível é a apreensão do ser da coisa que só pode ser formada, caso haja contato com a coisa. Pode-se entender o princípio de semelhança "o semelhante se conhece pelo semelhante" (simile simili cognoscitur), como um princípio de compatibilidade entre o intelecto e os $\operatorname{corpos}^{20}$. Mas essa compatibilidade, como sugere Perler, não dispensa as espécies como recursos cognitivos (kognitive Hilfsmittel) ${ }^{21}$.

Tomás parte da tese dos antigos naturalistas, que inviabilizava o conhecimento de modo geral em razão do fluxo contínuo das coisas corpóreas. Os corpos são mutáveis, móveis e, por estarem em constante mudança, a apreensão de algo acerca desses corpos se tornava impossível, excluindo qualquer possibilidade de certeza sobre a verdade das coisas. Esse argumento professa a dificuldade de se defender um conhecimento seguro. Como os filósofos antigos identificavam o sentido com o intelecto, o conhecimento a respeito de algo tornava-se indeterminado. O próprio intelecto não seria capaz de sustentar algo sobre esses objetos, já que não acompanharia as indeterminações dos

\footnotetext{
19 AQUINO, Tomás de. Suma de Teologia: primeira parte - questões 84-89. Tradução: Carlos Arthur Ribeiro Nascimento. 2. ed. Uberlândia: Edufu, 2010, p. 77.

${ }^{20}$ AQUINO, Tomás de. Suma de Teologia: primeira parte - questões 84-89. Tradução: Carlos Arthur Ribeiro Nascimento. 2. ed. Uberlândia: Edufu, 2010, p. 85.

${ }^{21}$ PERLER, Dominik. Theorien der Intentionalität im Mittelalter. 2nd ed. Frankfurt Am Main: Vittorio Klostermann, 2004, p. 83. A interpretação de Perler de que as espécies operam como recurso cognitivo na intelecção de objetos extramentais não deve ser entendida como mera duplicação acidental de objetos mentais. O conteúdo mental da espécie, no modo intencional, refere-se à forma do objeto extramental.
} 
sensíveis $^{22}$. Tomás segue, claramente, o que Aristóteles diz em sua Metafísica, Livro IV, acerca dos filósofos naturalistas.

Um segundo ponto destacado para invalidar o argumento platônico é o argumento do erro dos sentidos, segundo o qual os sentidos erram na apreensão e na formulação do conhecimento. Por essa razão, não podem ser considerados base para um conhecimento científico seguro. Essas duas teses (o fluxo e o engano dos sentidos) levaram alguns naturalistas a uma conclusão cética acerca do conhecimento que podemos ter sobre os objetos do mundo. $\mathrm{Na}$ análise tomista da interpretação dos filósofos antigos acerca da origem do conhecimento humano, os objetos no mundo não possuíam uma condição fixa de ser, estavam em constante mudança. Por causa disso, os sentidos eram facilmente enganados, tornando a ciência impossível. Henle destaca que Aquino considerava Platão um protagonista da verdade e da certeza, ou seja, da filosofia e da ciência. Platão negou a tese dos filósofos naturalistas de que a única realidade era a mutabilidade das coisas $^{23}$.

Tomás de Aquino, em Sententia Metaphysicae, lib. 4 I, 12, expõe que os naturalistas não distinguiam o intelecto do corpo, identificando, por vezes, o princípio da cognição humana com algum elemento natural. Eles consideravam as coisas sensíveis apenas pelo aspecto da indeterminação, que é referente ao aspecto da matéria. Por essa razão, atribuíram aos sensíveis a mutabilidade, não encontrando nada de determinado nas coisas sensíveis:

Não dizem a verdade, entretanto, com isso, porque estabelecem que não há nada determinado nas coisas sensíveis. Pois, ainda que a matéria seja considerada para muitas formas na medida em que é indeterminada, todavia, pela forma, (a matéria) é determinada para apenas um modo de ser. Disso, já que as

\footnotetext{
${ }^{22}$ AQUINO, Tomás de. Suma de Teologia: primeira parte - questões 84-89. Tradução: Carlos Arthur Ribeiro Nascimento. 2. ed. Uberlândia: Edufu, 2010, p. 78-79.

${ }^{23}$ HENLE, R. J. Saint Thomas and platonism: a study of the plato and platonici texts in the writings of Saint Thomas. The Hague: Martinus Nijhoff, 1970, p. 314.
} 
coisas são conhecidas mais por sua forma que por sua matéria, não se deve dizer que não seja possível um conhecimento de algumas coisas determinadas. E, por isso, como a opinião destes tem alguma verossimilhança, convém dizer tal como os mesmos disseram, como disse Epicarmo a Xenophane, que, porventura, sustentava que todas as coisas eram necessárias e imóveis e que eram conhecidas pela certeza. ${ }^{24}$

Claramente, nesta passagem, Tomás salienta que o conhecimento sensível deve ser entendido não apenas por sua indeterminação, mas por sua determinação, que é dada pela forma da coisa. A forma é o princípio que se conecta com a matéria e que confere a um objeto ou a um ser vivo uma estrutura. Os filósofos naturalistas se confundiram pelo movimento das coisas sensíveis e uma vez que todas as coisas estavam num fluxo, como afirmou Heráclito, o conhecimento verdadeiro não podia ser apreendido. Para Tomás, trata-se de considerar o ente como um composto de indeterminação, para o qual se possa atribuir um princípio de determinação, a forma. O ente é a composição de matéria e forma. Isso significa que a coisa está aberta à modificação e à mudança, entretanto pode-se obter dela um conhecimento verdadeiro e certo devido à forma nela instanciada.

Esse é o quadro em que Tomás de Aquino insere Platão, cujo mérito foi destacar o conhecimento inteligível. Na leitura de Tomás, Platão não admitiu que o ser de alguma coisa pudesse estar nos corpos sensíveis. Ao contrário, estaria em ideias separadas da realidade sensível.

\footnotetext{
${ }_{24}$ Tradução do autor. No original: "Non tamen verum dicunt in hoc quod ponunt nihil determinatum esse in rebus sensibilibus. Nam licet materia quantum est de se indeterminate se habeat ad multas formas, tamen per formam determinatur ad unum modum essendi. Unde cum res cognoscantur per suam formam magis quam per materiam, non est dicendum quod non possit haberi de rebus aliqua determinata cognitio. Et tamen quia verisimilitudinem aliquam habet eorum opinio, magis congruit dicere sicut ipsi dicebant, quam sicut dicit Epicharmus ad Xenophanem, qui forte dicebat omnia immobilia et necessaria esse, et per certitudinem sciri." (THOMAS, \& ALARCÓN, E. S. Thomae de Aquino Opera omnia. Pamplona: Ad Universitatis Studiorum Navarrensis, 2001. Disponível em: https://www.corpusthomisticum.org/iopera. html. Acesso em: 20 set. 2018).
} 
De fato, a natureza sensível estava em constante mudança e, consequentemente, nunca poderia produzir ou fundamentar um conhecimento certo. Para possibilitar a ciência, afirmou que os objetos deveriam estar numa condição distinta da condição das coisas sensíveis. Essa suposição o levou a assentir a existência de uma realidade que julgou ser estável para que o intelecto tivesse uma apreensão do ser da coisa. Para tal realidade, Platão sustentou que o intelecto seria a única parte da alma capaz de apreender essas realidades imutáveis. Estabeleceu, por sua vez, a certeza do conhecimento intelectual.

O caráter falho e relativo dos sensíveis não pode, segundo Platão, ser compatível com as características que a ciência estabelece para seu objeto: verdade e certeza. Os sentidos são do mesmo modo relativos, falhos e duvidosos, não podendo ser objetos do conhecimento. Nessa visão, o objeto do intelecto não pode ser a coisa externa. Para refutar essa assertiva dos filósofos antigos acerca da impossibilidade de apreensão do ser de alguma coisa, Platão sustentou que o conhecimento verdadeiro e certo está assentado em objetos que possuem determinação, estabelecendo um gênero de ente distinto do gênero dos entes sensíveis aliud genus entium ${ }^{25}$. Dessa forma, Platão estaria estabelecendo a distinção entre os sentidos e o intelecto, por conseguinte, duas instâncias: a sensível e a inteligível. De modo figurado, a realidade sensível não passa de uma sombra da realidade inteligível. $O$ ente real para o qual o intelecto deve se voltar são os entes inteligíveis, que são as ideias.

\section{3 - A RELAÇÃO ENTRE IDEIAS E ESPÉCIES: AS IDEIAS COMO IMPOSSIBILIDADE DAS CIÊNCIAS NATURAIS E O REALISMO DIRETO MODIFICADO COMO MELHOR EXPLICAÇÃO DA TEORIA DAS ESPÉCIES}

Primeiramente, é preciso explicar a relação terminológica entre ideia e espécie. Cícero, nas Discussões Tusculanas, traduziu ıठॄı

\footnotetext{
25 AQUINO, Tomás de. Suma de Teologia: primeira parte - questões 84-89. Tradução: Carlos Arthur Ribeiro Nascimento. 2. ed. Uberlândia: Edufu, 2010, p. 78.
} 
“E mesmo que não houvesse nada, como é tratado por Platão em todos os tópicos - pois julga nada haver que nasça e pereça, e existir apenas naquilo que seja sempre e tal qual é (aquele a denomina “ideia”, nós, "espécie")"26. Isso se conservou no latim, de modo que Tomás concorda que species é o termo correlato, também, para o sentido de ideas enquanto um "gênero de entes separado da matéria"27. Por conseguinte, na raiz etimológica, Tomás está tratando do mesmo conceito. Entretanto, em sua epistemologia, as ideias perdem o estatuto de fonte do conhecimento humano, enquanto formas separadas, sendo configuradas como protótipos dependentes da mente divina:

Após a consideração sobre a ciência de Deus (q. 14), resta que se considere sobre as ideias. Há três questões a esse respeito. Primeira: se acaso há ideias. Segunda: se há várias ou apenas uma. Terceira: se há ideias de tudo o que é conhecido por Deus [...] Respondo dizendo que é necessário sustentar-se que há ideias na mente divina. Com efeito, "ideia”, em grego é chamada em latim de "forma", donde, por meio das ideias, são inteligidas as formas de coisas diversas, que existem além das próprias coisas. Ora, a forma de alguma coisa além da própria coisa existente pode referir-se a dois: ou para que seja exemplar daquilo de que é dita forma, ou para que seja princípio de cognição daquilo, segundo o que se diz que as formas dos cognoscíveis têm ser no cognoscente. E é necessário que se sustentem as ideias no que diz respeito a $\operatorname{ambos}^{28}$.

As ideais assumem um lado positivo na teoria de Tomás, como doutrina do exemplarismo e do conhecimento, essência como exemplar e

${ }^{26}$ CÍCERO, M. T. Discussões tusculanas. Tradução: Bruno Fregni Bassetto. Uberlândia: Edufu, 2014.

${ }_{27}$ AQUINO, Tomás de. Suma de Teologia: primeira parte - questões 84-89. Tradução: Carlos Arthur Ribeiro Nascimento. 2. ed. Uberlândia: Edufu, 2010, p. 79.

${ }_{28}$ AQUINO, Tomás de. Suma Teológica, Primeira Parte, questão 15: sobre as ideias. Tradução: Carlos Eduardo de Oliveira. Discurso, São Paulo, n. 40, p. 309-328, 2012. Disponível em: https:// doi.org/10.11606/issn.2318-8863.discurso.2010.68302. Acesso em: 15 set. 2018. 
essência como meio do conhecimento. Entretanto, a doutrina das ideias divinas está fundada sobre premissas e argumentos bastante diferentes das premissas que a teoria platônica sustenta. As ideias platônicas são subsistentes e entidades distintas e como universais não incluem sentido algum da matéria. $O$ estatuto das ideias na mente divina, por outro lado, permite que o objeto do conhecimento seja locado no mundo da matéria e da mudança, possibilitando a definição das coisas naturais.

Tomás sustenta:

Sobrepondo-se a estes, Platão, para poder salvar que é tido por nós conhecimento certo da verdade pelo intelecto, sustentou, além do que é corporal, outro gênero de entes separado da matéria e do movimento, que denominou espécies ou ideias, por cuja participação cada um dos singulares e sensíveis é denominado homem, cavalo ou algo semelhante. Dizia, portanto, que as ciências e definições e tudo o que pertence ao ato do intelecto não se refere a estes corpos sensíveis, mas àqueles imateriais separados; de tal modo que a alma não intelija estes corpos, mas intelija as espécies separadas destes corporais ${ }^{29}$

Tomás louva a atitude de Platão de manter o conhecimento certo da verdade, em contraste ao argumento do fluxo sustentado pelos naturalistas. Por essa razão, para "salvar" (salvare) o conhecimento científico, as definições, pois estabeleceu como objeto para o intelecto as ideias. Tomás entende as ideias como um gênero de entes separados da matéria e do movimento. Para ele, o problema reside em estabelecer a impossibilidade do conhecimento das coisas concernentes à matéria e ao movimento, que são os corpos externos. O conhecimento humano não pode se referir aos corpos externos. Consequentemente, o conhecimento da matéria e do movimento,

29 AQUINO, Tomás de. Suma de Teologia: primeira parte - questões 84-89. Tradução: Carlos Arthur Ribeiro Nascimento. 2. ed. Uberlândia: Edufu, 2010, p. 79. 
caro ao programa aristotélico difundido no século XIII, não é possível. Outra consequência apontada por Tomás reside no fato de que as coisas que nos aparecem não poderiam ser explicadas por esses entes separados da matéria, pois diferem delas no ser, de modo que qualquer afirmação sobre as coisas externas seria inviabilizada. Por essa razão, Tomás sustenta que a ciência e as definições não se referem a esses entes separados, pois para ele, é possível inserir na definição de algo a matéria comum das coisas sensíveis, sendo possível referir-se às coisas naturais com um conhecimento certo.

Outro trecho da Suma de Teologia que merece um destaque ainda maior para essa discussão e que nos autoriza, finalmente, a defender o realismo direto modificado é o artigo 2 da Q. 85: Se as espécies inteligíveis, abstraídas das fantasias, estão para o nosso intelecto como o que é inteligido. Vejamos a seguir o trecho:

Ora, esta opinião mostra-se manifestamente falsa em virtude dos dois seguintes. Primeiro, com efeito, pois são os mesmo que inteligimos e de que se ocupam as ciências. Portanto, se os que inteligimos fossem apenas as espécies que estão na alma, seguir-se-ia que todas as ciências não seriam acerca das coisas que estão fora da alma, mas apenas acerca das espécies inteligíveis que estão na alma, assim como, de acordo com os platônicos, todas as ciências são acerca das ideias, que sustentavam que eram os inteligidos em ato $^{30}$.

Com esse trecho, Tomás quer dizer que as espécies não são aquilo que o intelecto apreende enquanto uma ideia, no sentido platônico, pois ele se refere às espécies que estão na alma e que a ciência trata sobre as coisas que estão fora da alma. Os platônicos teriam limitado a ciência às ideias e como objeto do intelecto as próprias ideias. Na concepção de Tomás, a potência cognitiva deve conhecer além de suas próprias afecções, caso

$3^{30}$ AQUINO, Tomás de. Suma de Teologia: primeira parte - questões 84-89. Tradução: Carlos Arthur Ribeiro Nascimento. 2. ed. Uberlândia: Edufu, 2010. 
contrário incorreria no erro dos antigos de que tudo que parece é verdadeiro, de modo que coisas contraditórias passariam a ser simultaneamente verdadeiras, pois a potência julgaria a sua própria afecção. Isto produziria um relativismo no juízo. Tomás conclui, afastando-se do platonismo e dos antigos, que a espécie é aquilo pelo qual (id quo) o intelecto intelige e não o que o intelecto intelige (id quod), mostrando assim que a espécie é mais um recurso cognitivo com o qual o intelecto pode se auxiliar para as coisas externas, e não a coisa inteligida, como supunham os platônicos.

Passemos para o último trecho a ser analisado e que encerra, por ora, a discussão acerca do primeiro e segundo objetos do intelecto:

Por isso, cumpre dizer que a espécie inteligível está para o intelecto como o pelo que o intelecto intelige. $\mathrm{O}$ que fica patente de maneira seguinte. Com efeito, como há uma dupla ação como se diz no livro IX da Metafísica, uma que permanece no agente como ver e inteligir, outra que passa à coisa externa, como esquentar e cortar, ambas se dão de acordo com alguma forma. E assim como a forma, de acordo com a qual se produz a ação que tende para a coisa externa, é uma semelhança do aquecido, igualmente a forma, de acordo com a qual se produz a ação que permanece no agente, é uma semelhança do objeto. Donde a semelhança da coisa visível ser o de acordo com o que a vista vê; e a semelhança da coisa inteligida, que é a espécie inteligível, é a forma de acordo com a qual o intelecto intelige. Mas visto que o intelecto reflete sobre si mesmo, de acordo com a mesma reflexão, intelige tanto o seu inteligir como a espécie pela qual intelige. Assim, a espécie intelectiva é secundariamente o que é inteligido. Mas o que é inteligido primeiro é a coisa da qual a espécie inteligível é a semelhança ${ }^{31}$.

${ }^{31}$ AQUINO, Tomás de. Suma de Teologia: primeira parte - questões 84-89. Tradução: Carlos Arthur Ribeiro Nascimento. 2. ed. Uberlândia: Edufu, 2010, p. 145. 
Essa argumentação afasta inteiramente o relativismo dos filósofos naturalistas e, também, das ideias como objetos para o intelecto. Introduzindo a noção de similitude ou semelhança, Tomás mostra que o intelecto pode conhecer as coisas que estão fora da alma. Através da similitude das coisas no intelecto, pode-se alcançar a natureza de cada coisa. Desse modo, Tomás sustenta com Aristóteles que a pedra não está na alma, mas a espécie da pedra (enquanto similitude da pedra) e que, no entanto, o que é conhecido é a pedra. Essa assertiva de que o intelecto pode inteligir a coisa externa através de recursos cognitivos, caracteriza um realismo direto modificado, uma vez que esses intermediários, no caso, as espécies, são similitudes das coisas externas e a única diferença dessa similitude para a coisa externa é o seu modo de existência. Como o intelecto humano pode se referir às coisas externas? A resposta é que o intelecto deve se referir às coisas externas, porque elas são causas do conhecimento humano, mas não meros intermediários causais. Cada coisa externa é portadora do princípio formal. Basta que minha atenção se dirija à coisa para apreender suas informações necessárias.

Adriaenssen traz uma analogia interessante para o conceito de espécie de Tomás, que é a noção de device, ou seja, um dispositivo com o qual podemos compatibilizar coisas de configurações diferentes, como é o caso das coisas materiais e imateriais (corpo e intelecto) ${ }^{32}$. A partir da noção de device (dispositivo), dá-se a compatibilidade entre os modos diferentes da coisa, ou seja, o modo de existir e o modo de conhecer: "Por isso, é próprio da capacidade da alma conhecer a forma existente individualmente na matéria corporal, não porém na medida em que está em tal matéria"33. Por conseguinte, o intelecto não se dirige à espécie, mas à coisa externa, como o exemplo da foto formulado por Perler, ou ainda, de diversos aparelhos tecnológicos, como televisores,

\footnotetext{
32 ADRIAENSSEN, Han Thomas. Representation and scepticism from Aquinas to Descartes. Cambridge: Cambridge University Press, 2017, p. 25.

33 AQUINO, Tomás de. Suma de Teologia: primeira parte - questões 84-89. Tradução: Carlos Arthur Ribeiro Nascimento. 2. ed. Uberlândia: Edufu, 2010, p. 133.
} 
smartphones e outros aparelhos com os quais podemos ter notícias de outros lugares ou acontecimentos.

\section{4 - CONCLUSÃO}

Para encerrar este artigo, podemos dizer que Platão ou o platonismo que encontramos na Suma de Tomás revela um tipo de acesso ao conhecimento dos pensamentos de Deus, o que é incompatível para com o intelecto humano. Por outro lado, mostra também uma impossibilidade de acesso ao objeto externo, como visto na Questão 85 , art. 2, pois a espécie seria o objeto do conhecimento tal como a ideia platônica. Similarmente, a teoria das ideias platônicas não parece defender um idealismo do tipo que sustenta a existência das coisas a partir da percepção dessas coisas, como sustenta Moore ${ }^{34}$. O platonismo defende a existência dessas realidades independentemente de qualquer afecção psíquica, traço característico do realismo, porém pelo princípio de semelhança a alma as conhece por si mesma, sem necessidade dos objetos externos no mundo.

Com relação à teoria das espécies de Tomás, não podemos sustentar inteiramente que a espécie seja o primeiro objeto do intelecto humano ou que ela seja o que o intelecto visa conhecer, pois isso resultaria num modelo de realismo indireto, em que o intelecto está condicionado aos seus modelos representacionais, de modo que o acesso à coisa externa fosse obstruído pela espécie. Tal tese é incompatível com a proposta de Tomás. A espécie não é a ideia separada das coisas, porque é abstração das condições inteligíveis de uma coisa sensível (da coisa externa). Ela é, ao mesmo tempo, a quididade da coisa conhecida enquanto o meio pelo qual se conhece a coisa externa. Nesse sentido, a espécie inteligível não pode ser entendida

34 AMATUCCI, Marcos. A refutação do idealismo. Synesis, Petrópolis, v. 7, n. 2, 2015, p. 116-188, jul./dez. 2015. Tradução de MOORE, G. E. The refutation of idealism. Disponível em: http://seer. ucp.br/seer/index.php/synesis/article/view/908/432. Acesso em: 20 set. 2018. 
como uma marca mental, como sustenta Panaccio ${ }^{35}$. O intelecto recebe as formas das coisas externas ao seu modo, que é o modo imaterial e imutável. O conhecimento do intelecto sobre as coisas externas é um conhecimento imaterial, universal e necessário ${ }^{36}$. Na argumentação de Tomás contra o platonismo, as espécies não são consideradas como acidental, mas como um conteúdo cognitivo que se reporta diretamente à coisa externa.

Assim, analisar o platonismo no artigo 1 da Q. 84 e no artigo 2 da Q. 85 , serviu para distinguir o realismo direto e o realismo direto modificado. Como consequência disso, deve-se dizer que a espécie pode ser tanto o id quo quanto o id quod. Isso sugere, ainda, um identidade formal entre a espécie e a coisa no mundo natural, pois olhar para espécie é olhar para a coisa no mundo. O que podemos concluir, além disso, é que, para Tomás, as formas devem estar instanciadas nas coisas naturais e a espécie deve ser ao modo do intelecto idêntica em seu conteúdo à forma da coisa, ou seja, o conteúdo de uma espécie não é nada além do que sua natureza, que também está instanciada na coisa material. Por essa razão, Tomás descarta as ideias platônicas que de um lado estabelecem as formas separadas das coisas materiais, e descarta o representacionalismo, que supõe uma mediação representacional da espécie para a coisa externa.

\section{REFERÊNCIAS}

AMATUCCI, Marcos. A refutação do idealismo. Synesis, Petrópolis, v. 7, n. 2, 2015, p. 116-188, jul./dez. 2015. Tradução de MOORE, G. E. The refutation of idealism. Disponível em: http://seer.ucp.br/seer/index.php/synesis/article/ view/908/432. Acesso em: 20 set. 2018.

AQUINO, Tomás de. Suma Teológica, Primeira Parte, questão 15: sobre as ideias. Tradução: Carlos Eduardo de Oliveira. Discurso, São Paulo, n. 40, p.

\footnotetext{
35 PANACCIO, Claude. Aquinas on Intellectual Representation. Cahiers d'Épistémologie, Montréal, n. 265, p. 03-21, 2000. Disponível em: https://www.yumpu.com/en/document/ read/27600278/cahiers-dapistamologie-uqam. Acesso em: 03 jan. 2019.

36 AQUINO, Tomás de. Suma de Teologia: primeira parte - questões 84-89. Tradução: Carlos Arthur Ribeiro Nascimento. 2. ed. Uberlândia: Edufu, 2010, p. 81.
} 
309-328, 2012. Disponível em: https://doi.org/10.11606/issn.2318-8863. discurso.2010.68302. Acesso em: 15 set. 2018. https://doi.org/10.11606/ issn.2318-8863.discurso.2010.68302

AQUINO, Tomás de. Suma de Teologia: primeira parte - questões 84-89. Tradução: Carlos Arthur Ribeiro Nascimento. 2. ed. Uberlândia: Edufu, 2010. https://doi.org/10.14393/edufu-978-85-7078-441-4

CíCERO, M. T. Discussões tusculanas. Tradução: Bruno Fregni Bassetto. Uberlândia: Edufu, 2014. https://doi.org/10.14393/EDUFU-978-85-7078-308-0

ADRIAENSSEN, Han Thomas. Representation and scepticism from Aquinas to Descartes. Cambridge: Cambridge University Press, 2017. https://doi. org/10.1017/9781316855102

BALTUTA, Elena. Aquinas on intellectual cognition: the case of intelligible species. Philosophia, [s. I.], v. 41, n. 3, p. 589-602, Sept. 2013. Disponível em: http://dx.doi.org/10.1007/s11406-013-9481-y. Acesso em: 20 set. 2018. https://doi.org/10.1007/s11406-013-9481-y

HENLE, R. J. Saint Thomas and platonism: a study of the plato and platonici texts in the writings of Saint Thomas. The Hague: Martinus Nijhoff, 1970. https://doi.org/10.1007/978-94-010-3167-7_1

KRETZMANN, Norman. Philosophy of mind. In: KRETZMANN, Norman; STUMP, Eleonore (org.). The Cambdridge companion to Aquinas. 5th ed. Cambridge: Cambridge University Press, 1998. p. 128-160. https://doi. org/10.1017/ccolo521431956.006

PASNAU, Robert. Theories of cognition in the later middle ages. Cambridge: Cambridge University Press, 1997.

PANACCIO, Claude. Aquinas on Intellectual Representation. Cahiers d'Épistémologie, Montréal, n. 265, p. 03-21, 2000. Disponível em: https://www. yumpu.com/en/document/read/27600278/cahiers-dapistamologie-uqam. Acesso em: 03 jan. 2019.

PERLER, Dominik. Essentialism and direct realism: some late medieval perspectives. Topoi, Amsterdan, v. 19, n. 2, p. 111-122, Dec. 2000. Disponível em: http://dx.doi.org/10.1023/a:1006425008627. Acesso em: 13 set. 2018.

PERLER, Dominik. Theorien der Intentionalität im Mittelalter. 2nd ed. Frankfurt Am Main: Vittorio Klostermann, 2004. https://doi.org/10.1163/1875673590000834 
THOMAS, \& ALARCÓN, E. S. Thomae de Aquino Opera omnia. Pamplona: Ad Universitatis Studiorum Navarrensis, 2001. Disponível em: https://www. corpusthomisticum.org/iopera.html. Acesso em: 20 set. 2018. 